\title{
Metastatic Endometrial Carcinoma
}

National Cancer Institute

\section{Source}

National Cancer Institute. Metastatic Endometrial Carcinoma. NCI Thesaurus. Code C156068.

A carcinoma that arises from the endometrium and has metastasized to another anatomic site. 